of cross reaction between Tamm-Horsfall glycoprotein in the renal tubular cells and in hepatocytes, is directed at both the kidney and liver antigens. Direct cross reaction with the liverspecific membrane lipoprotein, however, was thought to be unlikely as there was no reaction on immunodiffusion between this antigen and an antibody to Tamm-Horsfall glycoprotein. This has been confirmed by the present blocking experiments, since Tamm-Horsfall glycoprotein blocked only the reaction against kidney cells, while the liver-specific protein effectively reduced cytotoxicity only for liver cells.

The proposed mechanism for initiating sensitisation to Tamm-Horsfall glycoprotein is more easily visualised in patients with untreated chronic active hepatitis, in whom hepatocellular damage is a prominent histological feature and lymphocytemediated cytotoxicity for hepatocytes is a constant finding, ${ }^{6}$ than in those with primary biliary cirrhosis, in whom, at least in the early stages of the disease, the inflammatory reaction is confined to the bile ducts. As the disease progresses, however, the cellular inflammation tends to spread into the lobule and with this there may also be piecemeal necrosis of periportal hepatocytes. Sensitisation to hepatocyte membrane antigens might then occur, and it is in these cases that renal tubular acidosis may be expected to arise.

Whether the many other systemic manifestations, including Sjögrens syndrome, found in chronic active hepatitis and primary biliary cirrhosis are also induced secondary to the liver disease by cross-reacting antigens, or whether they are due to other mechanisms such as deposition of circulating immune complexes or a common genetic predisposition awaits further investigation.

We are indebted to Dr R D Marshall (St Mary's Hospital) for kindly supplying cultures of baby hamster kidney cells and to the Wellcome Trust for their continuing support.

\section{References}

1, Golding, P L, Smith, M G M, and Williams, R, American fournal of Medicine, 1973, 55, 772 .

2 Smith, M G M, et al, British Medical fournal, 1972, 1, 527.

3 Tsantoulos, D C, et al, British Medical fournal, 1974, 4, 491.

4 Rhodin, J, in Renal Disease, ed D A K Black, 2nd edn, p 58. Oxford, Blackwell, 1967.

${ }^{5}$ Dunstan, D R, et al, Proceedings of the Royal Society, London, series B, $1974,186,297$.

6 Thomson, A D, et al, Nature New Biology, 1974, 252, 721.

${ }^{7}$ Rocklin, R, Mayas, O, and David, J, Fournal of Immunology, 1970, 104, 95.

8 Boyum, A, Scandinavian fournal of Clinical and Laboratory Investigation, 1968, 21, suppl 97, p 9.

${ }^{9}$ Fletcher, A P, Neuberger, A, and Ratcliffe, W A, Biochemical fournal, $1970,120,417$.

10 Eddleston, A L W F, et al, British Medical fournal, 1973, 4, 274

11 Heide, K, and Schwick, H G, in Handbook of Experimental Immunology, vol I: Immunochemistry, 6.1, ed D M Weir. Oxford, Blackwell, 1973. 12 Cochrane, A M G, et al, Lancet, 1976, 1, 441.

\title{
Neuropathy in experimental diabetes: an animal model
}

\author{
J JAKOBSEN， K LUNDBÆK
}

British Medical fournal, 1976, 2, 278-279

\section{Summary}

A morphometric study of the common peroneal nerve in early experimental diabetes in rats showed that fibre size was diminished. The reduction in the size of the axon was twice that of the myelin sheath. This may contribute to the understanding of the impaired motor conduction velocity found in diabetics shortly after the onset of their disease.

\section{Introduction}

After many years of diabetes a few patients will develop signs and symptoms of disabling diabetic neuropathy. Most diabetics, however, can be shown to have asymptomatic neurological abnormalities soon after the clinical onset of their disease. These may be evaluated precisely from the motor conduction velocity. ${ }^{1}$ There is little information on the morphological basis of this early neurological disorder, partly because of the technical and ethical problems of performing nerve biopsies on patients without clinical signs of nervous disease. Attempts to construct an animal model of diabetic neuropathy to help explain diabetic nervous system disease have presented difficulties. In experimental diabetes-whether induced by alloxan, streptozotocin, or pancreatectomy - the same reduction of motor conduc-

University Institute of Pathology and Second University Clinic of Internal Medicine, Kommuehospitalet, 8000 Aarhus C, Denmark

J JAKOBSEN, MD, research fellow

K LUNDBÆK, MD, professor of medicine tion velocity is found as in diabetic patients. ${ }^{2-5}$ Morphological studies, however, have failed to show changes that could explain or be correlated with this conduction abnormality. ${ }^{4}$

We present the results of morphometric studies of peripheral nerves in early streptozotocin-induced diabetes in rats. A diminution in the size of the nerve fibres, especially the axons, was found, which may explain the impairment of nerve conduction.

\section{Methods}

For precise determination of nerve fibre size two points are important. Firstly, in cross-sections of peripheral nerves the fibres do not always appear as circles or ellipses but may take many other forms (fig 1). Use of a point-counting technique is therefore less likely to result in error than measurement of diameters. Secondly, because the size of nerve fibres increases with age, ${ }^{4}$ diabetic and control animals must be of the same age.

In the present study, diabetes was induced with streptozotocin in 10 male rats. During the experiment blood glucose values ranged from 16.7 to $33.3 \mathrm{mmol} / 1(300-600 \mathrm{mg} / 100 \mathrm{ml})$. After four weeks the two common peroneal nerves were fixed by vascular perfusion. Nerves from 10 control male rats-matched with the diabetic animals for age and weight-were treated likewise. The osmolality of the fixatives was maintained within a narrow range. Transverse semi-thin sections were cut from plastic-embedded tissue by placing the nerve perpendicular to the edge of the glass knife of the LKB Ultrotome with the aid of a 10-times-magnifying ocular fitted with cross-hairs. The identity of the specimens was unknown both to the technician making the sections and to JJ, who performed the measurements.

Representative samples of the fibre population of one of the common peroneal nerves from each animal were taken by random selection of circle sectors including an average of 250 fibres. Within the sectors the number of test points of a simple square lattice of 10 points/ 
$81.6 \mu \mathrm{m}^{2}$ falling on to the profiles of each fibre and its axon was counted. The internodal length and thickness of 20 isolated teased fibres from the other peroneal nerve of each animal were determined.

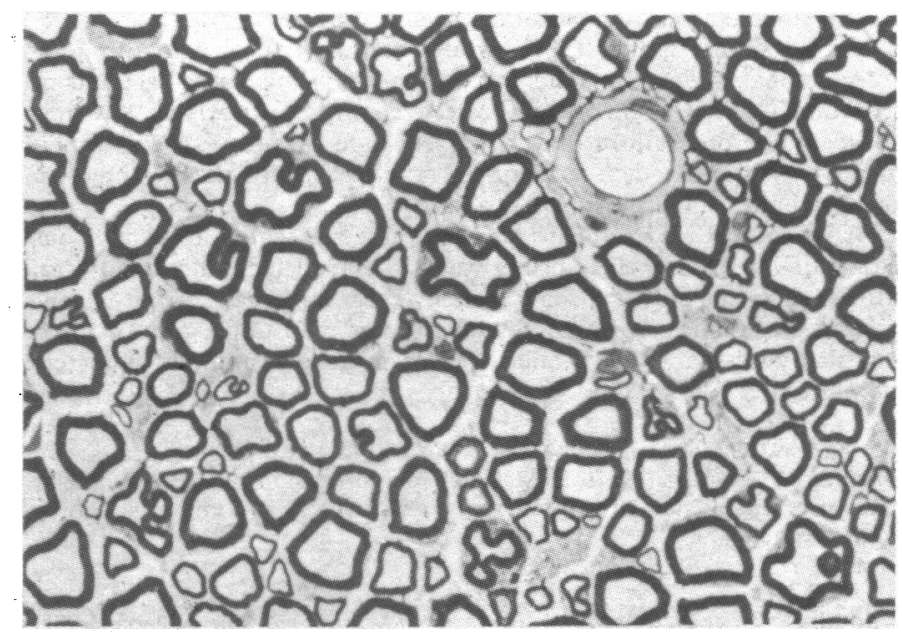

FIG 1-Semi-thin transverse section of part of common peroneal nerve showing different forms of nerve fibres. $(\times 865$. $)$

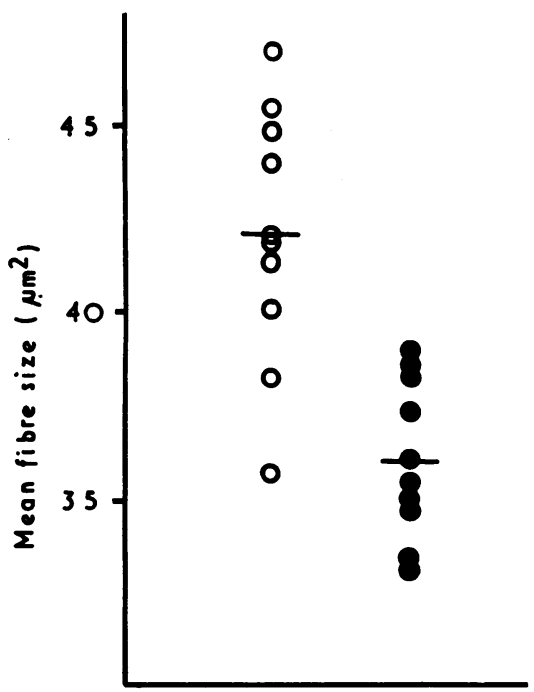

FIG 2-Mean cross-sectional fibre size in each of 10 control (0) and 10 diabetic rats (O).

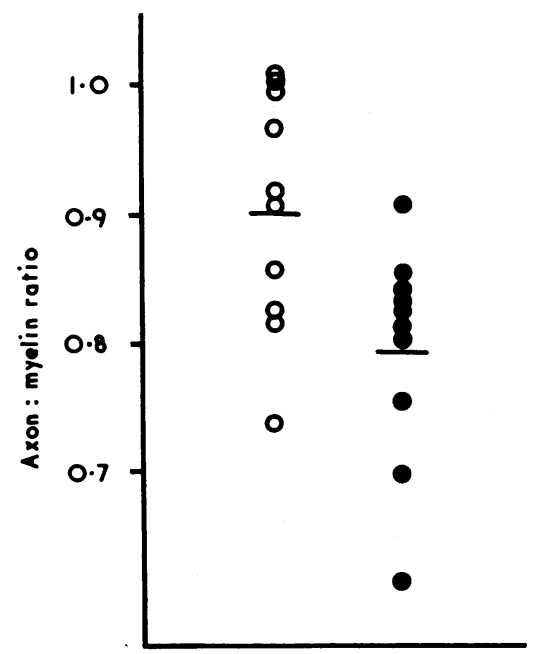

FIG 3-Axon:myelin ratio in each of 10 control (0) and 10 diabetic rats (O).

\section{Results}

Measurement of internodal length and thickness showed no evidence of segmental demyelination or remyelination. The numbers of myelinated fibres in the common peroneal nerves from the diabetic and control animals were $1881 \pm S D 111$ and $1870 \pm 108$ respectively. The mean fibre size in the nerve from each animal is shown in fig 2 . The arithmetic means in the diabetic and control groups were $36 \cdot 15 \pm 2 \cdot 12$ $\mu \mathrm{m}^{2}$ and $42.08 \pm 3.44 \mu \mathrm{m}^{2}$ respectively. This difference- $-14 \%$-is statistically highly significant $(P<0.001)$.

The mean fibre size in the nerve from each animal is shown in fig 2 . The

The axons were more diminished than the myelin sheaths. The mean cross-sectional area was $16.00 \pm 1.52 \mu \mathrm{m}^{2}$ in the diabetic group compared with $19.96 \pm 2.34{\mu \mathrm{m}^{2}}^{2}$ in the controls-a difference of $20 \%(P<0.001)$. The mean area of the myelin sheath was $20.15 \pm$ $1.29 \mu \mathrm{m}^{2}$ in the diabetic animals and $22.12 \pm 1.66 \mu \mathrm{m}^{2}$ in the controls $(\mathbf{P}<0.01)$. This is a difference of only $9 \%$. When the axon:myelin sheath ratios were calculated for each animal (fig 3 ) they were found to be lower in the diabetics $(P<0.02)$.

\section{Discussion}

These results show a diminution in the size of nerve fibres in early experimental diabetes. Sharma and Thomas, ${ }^{4}$ who studied peripheral nerves in rats with diabetes induced by streptozotocin and alloxan, concluded that the dimensions of the nerve fibres were normal. They, however, did not use a point-counting technique but measured fibre diameter (see above). Furthermore, the ages of the animals in their series varied considerably. In fact, in every case in which their diabetic and control animals can be matched for age the diabetic ones had thinner nerve fibres.

The use of a point-counting technique permitted individual estimates of axon and myelin sheath diminution to be made. The diminution of the axon appeared to be twice as great as that of the myelin sheath.

Our results may well provide a morphological basis for the explanation of reduced nerve conduction velocity in early experimental diabetes. ${ }^{2-5}$ With due caution they may be used in current discussion about myelin sheath or axon changes being the first stage of diabetic neuropathy in man. ${ }^{6-13}$ Since the reduction in the size of the axon was greater than that of the myelin sheath axon degeneration may be the initial lesion of diabetic neuropathy. This would agree with the conclusions of Bischoff ${ }^{13}$ and Greenbaum, ${ }^{8}$ who studied 11 patients with diabetes of recent onset. Severe segmental demyelination in long-standing diabetes, as demonstrated by Thomas and Lascelles, ${ }^{9-10}$ may well be secondary to axon degeneration.

It remains to be shown whether the changes caused by diabetes in the streptozotocin-treated rat can be prevented or reversed with insulin, as can the early abnormalities of motor conduction velocity in diabetic patients whose blood glucose level is kept at normal for one or two weeks. ${ }^{14}$ This is currently under investigation in our laboratory.

\section{References}

1 Gregersen, G, Neurology, 1967, 17, 972.

2 Eliasson, S G, fournal of Clinical Investigation, 1964, 43, 2353.

${ }^{3}$ Miyoshi, T, and Goto, I, Electroencephalography and Clinical Neurophysiology, 1973, 35, 125.

4 Sharma, A K, and Thomas, P K, Fournal of the Neurological Sciences, 1974, 23, 1 .

5 Greene, D A, DeJesus, P V, and Winegard, A I, Fournal of Clinical Investigation, 1975, 55, 1326.

${ }^{6}$ Martin, M M, Lancet, 1953, 1, 560.

7 Dolman, C L, Neurology, 1963, 13, 135.

${ }^{8}$ Greenbaum, D, et al, Brain, 1964, 87, 201.

9 Thomas, P K, and Lascelles, R G, Lancet, 1965, 1, 1355.

10 Thomas, P K, and Lascelles, R G, Quarterly fournal of Medicine, 1966 $35,489$.

11 Chopra, J S, Hurwitz, L J, and Montgomery, D A D, Brain, 1969, 92, 391.

12 Reske-Nielsen, E, and Lundbæk, K, Diabetologia, 1968, 4, 34.

13 Bischoff, A, in Vascular and Neurological Changes in Early Diabetes, ed R A Camerini-Dávalos and H S Cole, p 441. New York and London, Academic Press, 1973.

14 Gregersen, G, Diabetologia, 1968, 4, 273. 